\title{
Perceived Parental Expectations and Level of Stress among Adolescents: A Cross Sectional Study at Bagalkot
}

\author{
Shriharsha $C^{1}$, Prakash Jiddimani ${ }^{1}$, Deelip S. Natekar ${ }^{2}$ \\ ${ }^{1}$ Professor and HOD, Department of Psychiatric Nursing, BVVS Sajjalashree Institute of Nursing Sciences, \\ Navanagar, Bagalkot-587103, Karnataka, India. \\ ${ }^{1}$ M.Sc. Nursing, 2nd Year, Department of Psychiatric Nursing, BVVS Sajjalashree Institute of Nursing \\ Sciences, Navanagar, Bagalkot-587103, Karnataka, India. \\ ${ }^{2}$ Principal, BVVS Sajjalashree Institute of Nursing Sciences, Navanagar, Bagalkot-587103, Karnataka, India.
}

Corresponding Author: Shriharsha C.

\begin{abstract}
Background: Parental support is needed for every school student to achieve their academics and career expectations. However, when parents have high expectations rather than support, it would reflect in academics and career expectations of their children. When they could not achieve their parents' expectations, it prompts stress and impacts their academic achievement and career expectations.
\end{abstract}

Aims: The aim of the study was to find out the correlation between perceived parental expectations and level of stress among adolescents and its association with their sociodemographic variables.

Methodology: A structured questionnaire was developed to collect the demographic information, perceived parental expectations among adolescents was measured using structured rating scale and level of stress of adolescents was measured using Modified Dave Smith's stress scale from a sample of 100 adolescents who are studying in $8^{\text {th }}, 9^{\text {th }}$ and $10^{\text {th }}$ standards of Shri B.V.V sangha`s English Medium High School, Vidyagiri at Bagalkot in Karnataka state India, were selected by disproportionate stratified random sampling technique. Data were analyzed using descriptive and inferential statistics.

Findings: Majority (48\%) of parental expectations of adolescents had high expectations and majority (53\%) of adolescents had moderate stress. A positive correlation $(r=0.296)$ found between parental expectations and stress among adolescents. A significant association was found between the perceived parental expectations and birth order $\left(\chi^{2}=\right.$ 13.079; $\mathrm{P}<0.05)$ and number of siblings $\left(\chi^{2}=\right.$ 24.637; $\mathrm{P}<0.05)$ and a significant association was found between level of stress and family income $\left(\chi^{2}=14.710 ; \mathrm{P}<0.05\right)$ and birth order $\left(\chi^{2}=15.416 ; \mathrm{P}<0.05\right)$.

Conclusion: The overall findings of the study revealed that, there was a positive correlation found between the perceived parental expectations and level of stress among adolescents.

Key Words: Perceived parental expectations, stress and adolescents.

\section{INTRODUCTION}

Adolescence is the period of physical, psychological and social maturing from childhood to adulthood. Generally, the term adolescents refer to individuals between the ages of 10 to 19 years. Adolescence is a transitional stage of physical and psychological human development that generally occurs during the period from puberty to legal adulthood. ${ }^{1}$ At present, worldwide more than 1.2 billion are adolescents: this indicates that roughly one in every six persons is an adolescent. About 21\% of Indian population is adolescents (about 243 million). ${ }^{2}$ India has the largest population of adolescents in the world being home to 243 million individual 
aged 10-19years. Karnataka is third with $68.3 \%$ of its population in the 18years and above age group, also the states adolescents' population stood at $18.9 \%$ of its total population. ${ }^{3}$ Adolescence is a crucial period of time. The onset of psychological disorder may be fast stress mainly comes from academy test, interpersonal relations, relationship problems, life changes, family factor and career exploration. ${ }^{4}$ The number one health issue for young people is their mental health. About $70 \%$ of health problems and most mortality among the young arise as a result of mental health. Almost $75 \%$ of all mental disorder first emerges between the ages of $15-25 .{ }^{5}$ The parents tend to have high expectation for their children, and then they create a lot of pressure for their children to do their work and study hard. So, the children's take too much tension and stress to achieve a goal. Level of stress Adolescence is increasing with parental expectations. ${ }^{6}$ If the parents have low expectations on their child, the child may underperform and lose confidence in their abilities to achieve. They show symptoms of anger anxiety and depression. Too high expectation can also cause problems for children. Highly competitive goals that are impossible to achieve can cause children to procrastinate give up feel stressed and show the same symptoms of anger, anxiety and depression. 7 The parental stressors contributed to a lot of stress among adolescents due to parents being too strict, pressurizing, too much to do best in all the subjects, like of sufficient guidance in studies, parents loosing temper, demanding too much for domestic work after school hours which disturb studies argument with mother and father respectively. ${ }^{8}$

Considering the facts, it is clear that, the adolescents perceive high parental expectations and which is contributing the development of stress among them, the present study aims at assessing the correlation between perceived parental expectations and levels of stress among adolescents who are studying in selected high school of Bagalkot.

\section{Study Design and Participants:}

Present study was a Quantitative Non-experimental approach with descriptive correlation study conducted on $25^{\text {th }}$ February 2020. Sample size for the study is 100 adolescents who are in the age group of 13-20 years and selected high school of Bagalkot. Adolescents who were studying in $8^{\text {th }}, 9^{\text {th }}$ and $10^{\text {th }}$ standard and willing to participate were included in the study. Adolescents with sick at the time of data collection were also excluded from the study. Permission to conduct study was obtained from Principal of Shri B.V.V Sangha's English Medium High School, Vidyagiri of Bagalkot.

\section{Description of the Tool:}

The structured tool comprised consist of items seeking information regarding socio- demographic characteristic, structured rating scale with 30 items to assess the perceived parental expectations and Modified Dave Smith`s stress scale with 14 items to assess the level of stress among adolescents.

\section{Data Collection Procedure:}

Prior permissions were taken from relevant institutions before the beginning of data collection procedure. The study participants were selected at selected high school of Bagalkot. Every adolescent who fulfilled the inclusion criteria was approached for data collection. Consent was obtained by the participants. Purpose of the study was explained to the participants in the language understandable to them. All the information collected was based on the prepared tool.

\section{Data Analysis:}

Descriptive statistics such as frequencies were used for categorical variables. Association between perceived parental expectations and level of stress among adolescents was found using ChiSquare test. 
Shriharsha $C$ et.al. Perceived parental expectations and level of stress among adolescents: a cross sectional study at Bagalkot.

RESULT

\section{A: Sample characteristics}

Table 1: Socio demographic characteristics of adolescents. SLNO Socio - demographic characteristics

\begin{tabular}{|l|l|l|}
\hline 1. & AGE: & $\begin{array}{l}\text { Frequency } \\
(\mathbf{n = 1 0 0})\end{array}$ \\
\hline & 13 to 14 years & \\
\hline & 15 to 16 years & 29 \\
\hline & 17 to18 years & 31 \\
\hline & 19 to 20 years & 35 \\
\hline 2. & SEX: & 05 \\
\hline & Male & \\
\hline & Female & 51 \\
\hline 3. & RELIGION: & 49 \\
\hline & Hin & \\
\hline
\end{tabular}

\begin{tabular}{|l|l|l|}
\hline 3. & RELIGION: & \\
\hline & Hindu & 81 \\
\hline & Muslim & 13 \\
\hline & Christian & 06 \\
\hline 4. & YEAR OF THE STUDY: & \\
\hline
\end{tabular}

\begin{tabular}{|l|l|l|}
\hline 4. & YEAR OF THE STUDY: & \\
\hline & $8^{\text {th }}$ & 30 \\
\hline & $9^{\text {th }}$ & 30 \\
\hline & $10^{\text {th }}$ & 40 \\
\hline 5. & FATHER $`$ EDUCATION: & \\
\hline
\end{tabular}

\begin{tabular}{|l|l|l|}
\hline 5. & FATHER`S EDUCATION: & \\
\hline & No normal education & 09 \\
\hline & Primary education & 05 \\
\hline & Secondary education & 15 \\
\hline & PUC/Higher education & 15 \\
\hline & Graden & 33 \\
\hline
\end{tabular}

\begin{tabular}{|l|l|l|}
\hline & PUC/Higher education & 15 \\
\hline & Graduation & 33 \\
\hline & Post graduation and above & 23 \\
\hline 6. & MOTHERS EDUCATION: & \\
\hline & No & 18 ormal education
\end{tabular}

\begin{tabular}{|l|l|l|}
\hline 6. & MOTHERS EDUCATION: & \\
\hline & No normal education & 18 \\
\hline & Primary education & 22 \\
\hline & Secondary education & 16 \\
\hline & PUC/Higher education & 25 \\
\hline & Graduation & 11 \\
\hline & Post graduation and above & 08 \\
\hline
\end{tabular}

\begin{tabular}{|l|l|l|}
\hline & Post graduation and above & 08 \\
\hline 7. & FATHER OCCUPATION: & \\
\hline & Labour work & 16 \\
\hline & Agriculture & 20 \\
\hline & Seff-ere & 31 \\
\hline
\end{tabular}

\begin{tabular}{|l|l|l|}
\hline & Self-employed & 31 \\
\hline & Employed & 33 \\
\hline 8. & MOTHERS OCCUPATION: & \\
\hline & House wife & 73 \\
\hline & L & 05 \\
\hline
\end{tabular}

\begin{tabular}{|c|c|c|}
\hline & Labour work & 05 \\
\hline & Agriculture & 02 \\
\hline & Self-employed & 12 \\
\hline & Employed & 08 \\
\hline 9. & FAMILY INCOME: & \\
\hline
\end{tabular}

\begin{tabular}{|l|l|l|}
\hline 9. & FAMILY INCOME: & \\
\hline & Less than Rs. 5000 & 17 \\
\hline & Rs.5000 to 8000 & 13 \\
\hline & Rs.8001 to 12000 & 22 \\
\hline & Rs.12001 \& above & 48 \\
\hline 10. & AREA OF RESIDENCE:
\end{tabular}

\begin{tabular}{|l|l|l|}
\hline & Rs.12001 \& above & 48 \\
\hline 10. & AREA OF RESIDENCE: & \\
\hline & Rural & 35 \\
\hline & Urban & 65 \\
\hline
\end{tabular}

\begin{tabular}{|l|l|l|}
\hline & Urban & 35 \\
\hline 11. & TYPE OF FAMILY: & 65 \\
\hline & Nuclear family & 57 \\
\hline & Joint family & 43 \\
\hline 12. & BIRTH ORDER: & \\
\hline & First & 35 \\
\hline & Second & 37 \\
\hline & Third & 20 \\
\hline & Forth and above & 08 \\
\hline 13. & NUMBER OF SIBLING: & \\
\hline & 1 & 43 \\
\hline & 2 & 36 \\
\hline & 3 & 20 \\
\hline & 4 and above & 01 \\
\hline
\end{tabular}

Socio-demographic characteristics of adolescents are presented in Table 1 . A most of adolescents(35\%) were to 17-18 years of age, most of (51\%) of were males, majority(81\%) were belonging to Hindu community, most of adolescents(40\%) were from $10^{\text {th }}$ standards, most of adolescents fathers(33\%) completed graduation, most of adolescents mothers(25\%) had completed PUC/Higher education, fathers occupation most(31\%) were employed, mothers occupation most(73\%) were house wives, majority(48\%) of family monthly income was more than 12000 , most (65\%) of adolescents from urban area, most (57\%) of them from nuclear family, most(37\%) of adolescents birth order was second and most(43\%) of their number of sibling had one.

\section{B: Assessment of levels of perceived parental expectations and level of stress among adolescents.}

Findings reveal that majority of the levels of the perceived parental expectations (48\%) had high parental expectations (Table2) and majority of the levels of the stress (53\%) had moderate stress among adolescents (Table3).

Table 2: Levels of perceived parental expectations among adolescents.

\begin{tabular}{|l|l|l|}
\hline $\begin{array}{l}\text { Levels of parental } \\
\text { expectations }\end{array}$ & $\begin{array}{l}\text { Range of } \\
\text { scores }\end{array}$ & Frequency \\
\hline High parental expectations & 61 to 90 & 48 \\
\hline Moderate parental expectations & 31 to 60 & 47 \\
\hline Low parental expectations & 00 to 30 & 5 \\
\hline
\end{tabular}

Table 3: Levels of stress among adolescents.

\begin{tabular}{|l|l|l|}
\hline Levels of stress & Range of scores & Frequency \\
\hline High stress & 29 to 42 & 15 \\
\hline Moderate stress & 15 to 28 & 53 \\
\hline Low stress & 00 to 14 & 32 \\
\hline
\end{tabular}

\section{C: Correlation between perceived parental expectations and stress among adolescents.}

Table 4: Levels of stress among adolescents.

Correlation between Perceived parental expectations and Stress

\begin{tabular}{|l|l|}
\hline Correlation coefficient (r) & $0.296^{* *}$ \\
\hline & $* * P<0.05$
\end{tabular}

A significant positive correlation was found between perceived parental 
Shriharsha $C$ et.al. Perceived parental expectations and level of stress among adolescents: a cross sectional study at Bagalkot.

expectations and stress among adolescents (Table 4).

\section{D: Association of the perceived parental expectations and stress of adolescents with their selected socio-demographic variables.}

Table 5: Association between levels of perceived parental expectations and socio-demographic variables.

\begin{tabular}{|c|c|c|c|}
\hline $\begin{array}{l}\text { Sl } \\
\text { No. }\end{array}$ & $\begin{array}{l}\text { Socio-demographic } \\
\text { variables }\end{array}$ & Df & $\begin{array}{l}\text { Chi-square } \\
\text { value }\end{array}$ \\
\hline 1. & Age & 6 & 3.908 \\
\hline 2. & Sex & 2 & 0.181 \\
\hline 3. & Religion & 4 & 3.641 \\
\hline 4. & Year of Study & 4 & 3.426 \\
\hline 5. & Father's educational status & 10 & 13.035 \\
\hline 6. & Mother's educational status & 10 & 7.096 \\
\hline 7. & Father's occupation & 6 & 5.346 \\
\hline 8. & Mother's occupation & 8 & 10.667 \\
\hline 9. & Family income & 6 & 2.537 \\
\hline 10. & Area of Residence & 2 & 5.016 \\
\hline 11. & Type of family & 2 & 0.303 \\
\hline 12. & Birth order & 6 & 13.079 \\
\hline 13. & Number of siblings & 6 & 24.637 \\
\hline
\end{tabular}

Table 5 shows the Association between perceived parental expectations and socio-demographic variables of adolescents. A significant association was found between the perceived parental expectations and birth order and number of siblings.

Table 6: Association between levels of stress and sociodemographic variables of adolescents.

\begin{tabular}{|l|l|l|l|}
\hline Sl.No & $\begin{array}{l}\text { Socio-demographic } \\
\text { variables }\end{array}$ & Df & $\begin{array}{l}\text { Chi-square } \\
\text { value }\end{array}$ \\
\hline 1. & Age & 6 & 4.327 \\
\hline 2. & Sex & 2 & 0.855 \\
\hline 3. & Religion & 4 & 2.481 \\
\hline 4. & Year of Study & 4 & 3.073 \\
\hline 5. & Father's educational status & 10 & 9.784 \\
\hline 6. & Mother's educational status & 10 & 7.308 \\
\hline 7. & Father's occupation & 6 & 7.808 \\
\hline 8. & Mother's occupation & 8 & 8.217 \\
\hline 9. & Monthly income of family & 6 & 14.710 \\
\hline 10. & Area of Residence & 2 & 5.188 \\
\hline 11. & Type of family & 2 & 0.159 \\
\hline 12. & Birth order & 6 & 15.416 \\
\hline 13. & Number of siblings & 6 & 4.449 \\
\hline \multicolumn{4}{|l|}{} \\
\hline
\end{tabular}

Table 6 shows the association between the stress and socio-demographic variables of adolescents. Findings revel that, a significant association was found between the stress of adolescents and monthly family income and birth order.

\section{DISCUSSION}

The main objective of the present study was conducted to find out the correlation between perceived parental expectations and level of stress among adolescents and its association with their socio-demographic variables. The study includes a sample of 100 adolescents who are studying in Shri B.V.V Sangha's English Medium High School, Vidyagiri at Bagalkot. Findings reveals that majority of the levels of the perceived parental expectations (48\%) had high parental expectations and majority of the levels of the stress (53\%) had moderate stress among adolescents and a significant association was found between perceived parental expectation and socio-demographic variables are birth order and number of siblings and a significant association was found between level of stress and sociodemographic variables are monthly family income and birth order. Similar study conducted by Neni S W, Latif AZ, Wong SY to determine the correlation between perceived parental expectations and level of stress among adolescents of East cost Penisular Malaysia, finding shows that year of the study and parental ambitions were important factors influencing stress level of adolescents ${ }^{9}$.

In the present study significant association was found between perceived parental expectation and socio-demographic variables. Similar findings were found in the study conducted to assess the perceived parental expectations of adolescents in Silesia; results showed that, the perceived parental expectations scores were significantly associated with year of the study with year of the study, parental expectation and occupation. ${ }^{10}$

In the present study significant association was found between level of stress and socio-demographic variables. Similar findings were found in the study conducted to assess the levels of stress of adolescents in Vietnam, results showed that, a significant association was found between stress and socio-demographic characteristics 
Shriharsha $C$ et.al. Perceived parental expectations and level of stress among adolescents: a cross sectional study at Bagalkot.

like year of study, parental ambition, family income and religious background. ${ }^{11}$

\section{CONCLUSION}

In the present study it is significantly positive correlation between perceived parental expectations and levels of stress among adolescents and where significantly association was found between perceived parental expectations and levels of stress with their socio-demographic variables.

Ethical Clearance: Ethical clearance was obtained from the Institutional ethical committee of BVVS Sajjalashree Institute of Nursing Sciences, Bagalkot.

\section{Source of Funding: Self}

\section{Acknowledgement: None}

\section{Conflict of Interest: Nil}

\section{REFERENCES}

1. Den A, Adolescents, 2016 Jun; Available from URL: http:// www.wikipedia. org/wiki/Adolescents.htm.

2. Sivagurunathan C, Umadevi R and Gopalakrishnan S. "Adolescent health: present status and its related programmes in India. Are we in the right direction?.” Journal of clinical and diagnostic research :JCDR vol. 9,3 (2015): LE01-6. doi:10.7860/ JCDR/2015/11199.5649.

3. Green, HMC Ginnity, A. Meltzer A, et al. Mental health of children and young people in world. 2 Feb 2019.\& URL:http://www.healthlibrary/adolescents.h tml.
4. Sawyer. Young people statistics.5 April 2018; Available from: URL:http:// www.youngsmindss.org. UK.

5. Collishaw.S. Time trends in adolescent's mental health, journal of child psychology and psychiatry.2015 Dec; 18(34):243-276.

6. Baker P. School education news. 2018 January 02. Available from: URL: http://www.education.wisc.edu/soc/news.

7. Wang L. Development and validation of a scale to measure the discrepancy of Parental Expectations, dissertation abstracts international2017 Jul; 45(10): 6643B (UMI No. 9708519).

8. Tomiki K. Achievement motivation and psychological well-being in Asian American college students: The contribution of intergenerational congruence of Academic expectations, dissertation abstracts international. 4 May 2016; 61(07): 3883B (UMI No. 9979834).

9. Neni. SW, Latif AZ, Wong SY and Lia PL.To determine the correlation between perceived parental expectations and levels of stress among adolescents of East Coast Peninsular Malaysia. Apr 2018; ISSN: 2345-4776.

10. Labuz-Roszak B, Pierzchala K, Kapinos M.Perceived parental expectations ofadolescents in Silesia,1225684 [Pub Med - indexed for MEDLINE] 2018 jun;65(3)

11. Tuan NA, Cuong le Q, Allebeck P, Chuc NT, Tomson T. Assess the levels of stres of adolescents in Vietnam. 2019Feb 13; doi: 10.1037/a0027645.

How to cite this article: Shriharsha C, Jiddimani P, Natekar DS. Perceived parental expectations and level of stress among adolescents: a cross sectional study at Bagalkot. International Journal of Science \& Healthcare Research. 2021; 6(4): 366-370. DOI: https://doi.org/10. 52403/ijshr.20211051 